\title{
Lisina em Rações para Suínos Machos Castrados Selecionados para Deposição de Carne Magra na Carcaça dos 95 aos 110 kg1
}

\section{Alexandre Luiz Siqueira de Oliveira², Juarez Lopes Donzele ${ }^{3}$, Rita Flávia Miranda de Oliveira ${ }^{3}$, Darci Clementino Lopes $^{3}$, Antonio Marcos Souto Moita ${ }^{4}$, Francisco Carlos de Oliveira Silva ${ }^{5}$, Letícia Silva de Freitas ${ }^{6}$}

\begin{abstract}
RESUMO - Foram utilizados 60 suínos machos castrados, provenientes de cruzamento entre híbridos comerciais, com peso inicial médio de 95,7 \pm 0,8 kg e final de 109,8 $\pm 1,1 \mathrm{~kg}$ para avaliar diferentes níveis de lisina sobre o desempenho e as características de carcaça. Foi usado o delineamento de blocos ao acaso, com cinco tratamentos, seis repetições e dois animais por repetição. Os tratamentos corresponderam a uma ração basal com 13,7\% de proteína bruta, 3367 kcal de ED/kg e suplementada com cinco níveis de L-lisina-HCl, resultando em rações com 0,50;0,60; 0,70;0,80 e 0,90\% de lisina total. O consumo de ração diário reduziu de forma linear. Entretanto, ficou caracterizada maior ingestão de lisina com o aumento da concentração dietética do aminoácido. Verificou-se efeito quadrático do nível de lisina sobre a conversão alimentar, que melhorou até o nível de $0,76 \%$ de lisina, e sobre a conversão alimentar em músculo, que reduziu de forma linear. No entanto, os dados ajustados pelo modelo "Linear Response Plateau" indicaram o nível de $0,79 \%$ para a melhor conversão alimentar em músculo. O ganho de peso, comprimento de carcaça, espessura de toucinho, rendimento de pernil, rendimento de carne magra e a área de olho de lombo não foram influenciados pelos tratamentos. Para o genótipo estudado, o nível de $0,76 \%$ de lisina total na ração foi o indicado para machos castrados, dos 95 aos $110 \mathrm{~kg}$, correspondendo à ingestão diária estimada de 23,8 g de lisina.
\end{abstract}

Palavras-chave: carcaça, exigência, terminação, genótipo, conversão alimentar em músculo

\section{Lysine in Rations for Barrows Selected for Lean Carcass Deposition from 95 to $110 \mathrm{~kg}$}

ABSTRACT - Sixty barrows from crossing between commercial hybrids with an average initial weight of $95.7 \pm 0.80 \mathrm{~kg}$ and an average final weight of $109.8 \pm 1.13 \mathrm{~kg}$ were used to evaluate different dietary lysine levels on performance and on carcass characteristics. The experimental design used was a randomized blocks with five treatments, six replicates and two animals per replicate. The treatments corresponded to a basal diet with $13.7 \%$ of crude protein, $3367 \mathrm{kcal} \mathrm{DE} / \mathrm{kg}$ supplemented with five L-lysine-HCl levels, resulting in diets with $0.50 ; 0.60 ; 0.70 ; 0.80$ and $0.90 \%$ of total lysine. The daily feed intake reduced by linear way with the increase of lysine level in diet. However, it was showed highest lysine consumption with increase of dietary aminoacid concentration. It was verified quadratic effect of treatments on the feed:gain ratio which improved until the level of $0.76 \%$ of lysine level and on feed:lean gain that reduced by linear way. However the adjusted data by Linear Response Plateau indicated the level of $0.79 \%$ to the best feed:lean gain. The weight gain, carcass lenght, backfat thickness, ham yield, lean growth yield and loin eye area were not influenced by treatments. For the genotype studied, it was concluded that barrows from 95 to $110 \mathrm{~kg}$ require $0.76 \%$ of total lysine in diet, corresponding to a daily lysine intake of $23.8 \mathrm{~g}$.

Key Words: carcass, requirement, finishing, genotype, feed:lean gain

\section{Introdução}

Existe, por parte do mercado consumidor, uma tendência em diminuir o consumo de gordura de origem animal. Para satisfazer estas exigências, pesquisas na área de melhoramento genético de suínos vêm sendo desenvolvidas no sentido de diminuir a deposição de gordura, obtendo assim maior eficiência de ganho em carne e maior porcentagem de carne magra na carcaça dos animais.
Isso possibilitou elevar o peso de abate dos animais com pouco comprometimento na qualidade da carcaça. No entanto, à medida que se aumenta o peso de abate dos animais, reduz-se a eficiência no ganho protéico, em função da queda na taxa de deposição diária de proteína na carcaça.

Nesse sentido, a adoção desta prática permite algumas vantagens ao produtor, dentre as quais podese destacar: redução nos custos por unidade de peso produzido, sem a necessidade do aumento no número

\footnotetext{
1 Parte da Tese de Mestrado do primeiro autor. Projeto apoiado pela AGROCERES.

2 Estudante de Doutorado do DZO/UFV. Bolsista do CNPq. E.mail: alextab@hotmail.com

3 Professores do DZO/UFV. E.mail: donzele@ufv.br; flavia@ufv.br; dclopes@ufv.br

4 Pesquisador da Agroceres.

5 Pesquisador da EPAMIG/CTZM. E.mail: fcosilva@epamig.ufv.br

${ }^{6}$ Bolsista de Iniciação Científica/FAPEMIG - DZO/UFV.
} 
de matrizes; aumento no rendimento de carcaça; e redução das perdas por resfriamento e processamento.

A indústria opta pelo abate de animais com maior peso, devido ao fato de que torna-se mais econômico processar carcaças mais pesadas, uma vez que os custos fixos, por unidade de peso, são diluídos em cima de uma maior quantidade de produto.

Uma vez que as exigências nutricionais dos suínos variam de acordo com a fase do crescimento, devido a alterações na composição do ganho, as necessidades nutricionais devem ser bem especificadas segundo o intervalo de peso, visandose o máximo rendimento de carne na carcaça.

Desta forma, torna-se imprescindível a avaliação das necessidades nutricionais de aminoácidos para suínos, especialmente a de lisina, devido à sua importância na deposição de tecido muscular.

Objetivou-se neste estudo avaliar o efeito dos níveis de lisina da ração sobre o desempenho produtivo e a qualidade da carcaça de suínos dos 95 aos $110 \mathrm{~kg}$ de peso, machos castrados selecionados para deposição de carne magra.

\section{Material e Métodos}

O experimento foi conduzido no Setor de Suinocultura do Departamento de Zootecnia, do Centro de Ciências Agrárias da Universidade Federal de Viçosa, em Viçosa - MG.

Foram utilizados 60 suínos machos castrados, híbridos comerciais, com peso médio inicial de 95,7 \pm $0,80 \mathrm{~kg}$. $\mathrm{O}$ delineamento experimental adotado foi $\mathrm{o}$ de blocos ao acaso, com cinco tratamentos (níveis de lisina), seis repetições e dois animais por repetição. Para a distribuição dos animais dentro de cada bloco adotou-se, como critério, o peso inicial e o parentesco dos animais. Os tratamentos aplicados foram: 0,50; 0,$60 ; 0,70 ; 0,80$ e $0,90 \%$ de lisina total.

Os animais foram alojados em baias providas de comedouro semi-automático e bebedouro tipo chupeta, localizadas em galpão de alvenaria, com piso de concreto, teto rebaixado e cobertura de telha de barro. A limpeza das baias foi realizada diariamente com raspagem dos dejetos e lavagem com água.

Os animais foram pesados no início e final do período experimental, quando atingiram 109,5 $\pm 1,13 \mathrm{~kg}$, para determinação do ganho de peso diário. As rações fornecidas e as sobras de ração foram pesadas semanalmente, para posterior determinação do consumo de ração diário, consumo de lisina diário e conversão alimentar.

A temperatura do ar foi registrada diariamente por meio de dois termômetros, de máxima e mínima, colocados no interior do galpão.

As rações experimentais, isoenergéticas e isoprotéicas (Tabela 1), eram à base de milho, farelo de soja e glúten de milho, suplementadas com LLisina- $\mathrm{HCl} 78,4 \%$, resultando em níveis de 0,$50 ; 0,60$; 0,70 e $0,80 \%$ de lisina total. Para os demais nutrientes foram adotadas as recomendações do NRC (1998). Em todos os níveis de lisina avaliados a relação entre a lisina e os demais aminoácidos essenciais foi, no mínimo, igual à preconizada por Fuller (1996).

A fim de manter as rações isonitrogenadas, a adição de lisina foi feita em substituição proporcional ao ácido glutâmico com base nos seus valores em proteína. As rações e a água foram fornecidas aos animais à vontade.

As análises bromatológicas dos ingredientes foram realizadas no Laboratório de Nutrição Animal do Departamento de Zootecnia da UFV, conforme metodologia descrita por Silva (1990).

No final do experimento, após jejum alimentar de 24 horas e de água nas últimas 12 horas, seis animais de cada tratamento foram abatidos. $\mathrm{O}$ abate ocorreu por dessensibilização mecânica e sangramento sendo, em seguida, as carcaças inteiras depiladas com auxílio de lança-chamas, evisceradas e pesadas em balança eletrônica. As carcaças foram serradas ao longo da coluna vertebral e as meia carcaças pesadas separadamente. Em seguida, na meia-carcaça direita, foram feitas medidas lineares de carcaça e, após permanecerem 24 horas em câmara fria à temperatura de 4 a $8^{\circ} \mathrm{C}$, estas foram espostejadas.

$\mathrm{Na}$ avaliação de carcaças, foram consideradas as seguintes medidas: comprimento, realizado pelo método brasileiro de classificação de carcaça (CCMB) (Associação..., 1973) e pelo método americano, da primeira costela à sínfise pubiana, segundo Boggs \& Merkell (1979); espessura de toucinho entre a última e a penúltima vértebra lombar (ETUL), espessura de toucinho a 6,5 cm da linha dorso-lombar (ETP2) e área de olho de lombo (AOL) (ABCS, 1973); rendimento de carcaça (expresso em porcentagem como peso da carcaça quente em relação ao peso de abate após jejum), rendimento de gordura (expresso em porcentagem como peso da gordura total, dissecada da carcaça, em relação ao peso da carcaça resfriada); e rendimento de pernil (expresso em porcentagem como peso total do pernil em relação ao peso da meia- 
Tabela 1 - Composição centesimal das rações experimentais

Table 1 - Centesimal composition of the experimental rations

Ingredientes $(\%)$

Ingredients
Níveis de lisina $(\%)$

Lysine level (\%)

Milho (7,69\%PB) (Corn, $7.69 \%$ CP $)^{1}$

Farelo de soja (45,5\%PB) (Soybean meal,45.5\% CP $)^{1}$

Glúten de milho $(60 \% \mathrm{~PB})$ (Corn gluten, $60 \% \mathrm{CP})^{1}$

L-Lisina $\mathrm{HCl}(78,4 \%)$ (L-lysine $\mathrm{HCl}, 78.4 \%)$

L-Treonina-98,5\% (L-threonine, $98.5 \%$ )

DL-Metionina-99\% (DL-methionine, 99\%)

L-Triptofano-99\% (L-tryptophan, 99\%)

L-Isoleucina-99\% (L-isoleucin, 99\%)

L-Valina-99\% (L-valine ,99\%)

Ácido glutâmico (Glutamic acid)

Núcleo vitamínico mineral (Mineral vitamin mix) ${ }^{2}$

Areia lavada (Washed sand)

Composição calculada ${ }^{3}$

Calculated composition

Proteína bruta (\%) (Crude protein)

Energia digestível $(\mathrm{kcal} / \mathrm{kg})$ (Digestible energy)

Lisina total (\%) (Total lysine)

Lisina digestível $(\%)^{4}$ (Digestible lysine)

Met.+ Cist. digestível $(\%)^{4}$ (Digestible Met.+ Cys.)

Treonina digestível $(\%)^{4}$ (Digestible threonine)

Triptofano digestível $(\%)^{4}$ (Digestible tryptophan)

Isoleucina digestível $(\%)^{4}$ (Digestible isoleucin)

Valina digestível $(\%)^{4}$ (Digestible valine)

Cálcio (\%) (Calcium)

Fósforo total (\%) (Total phosphorus)

\begin{tabular}{ccccc}
13,7 & 13,7 & 13,7 & 13,7 & 13,7 \\
3367 & 3367 & 3367 & 3367 & 3367 \\
0,500 & 0,600 & 0,700 & 0,800 & 0,900 \\
0,423 & 0,523 & 0,623 & 0,723 & 0,823 \\
0,458 & 0,458 & 0,458 & 0,470 & 0,535 \\
0,132 & 0,132 & 0,132 & 0,138 & 0,157 \\
0,437 & 0,437 & 0,437 & 0,507 & 0,577 \\
0,487 & 0,487 & 0,487 & 0,487 & 0,494 \\
0,545 & 0,545 & 0,545 & 0,545 & 0,560 \\
0,600 & 0,600 & 0,600 & 0,600 & 0,600 \\
0,450 & 0,450 & 0,450 & 0,450 & 0,450 \\
\hline
\end{tabular}

${ }^{1}$ Valores obtidos no Laboratório de Nutrição Animal do DZO/UFV, de acordo com metodologia descrita por Silva (1990).

1 Values obtained in Animal Nutrition Laboratory - DZO-UFV, according to Silva (1990).

${ }^{2}$ Contêm em $1 \mathrm{~kg}$ (Contents $/ \mathrm{kg}$ ): Ácido fólico (folic acid), $9 \mathrm{mg}$; Ácido pantotênico(pantotenic acid), 177 mg; Antioxidante (antioxidant), $1030 \mathrm{mg}$; Biotina (biotin), 1,4 mg; Ca, 177 g; Co, 3,7 mg; Cu, 2126 mg; Fe, 1932mg; Fl (máx.), 238 mg; P, 25 g; I, 29,5 mg; Mn, 936 mg; Niacina(niacin), 426 mg; Piridoxina (piridoxin), 13,3 mg; Promotor de crescimento (growth promoter), 1235 mg; Riboflavina (riboflavin), $71 \mathrm{mg} ; \mathrm{Se}, 8 \mathrm{mg} ; \mathrm{Na}$, 49g; Fósforo solubil. ácido cítrico (Phosphorus solved at citric acid), 90\%; Tiamina(tiamin), 13,3 mg; Vit. A, 93000 UI/kg; Vit. B 12,520 mcg; Vit. $\mathrm{D}_{3}, 24000 \mathrm{Ul} / \mathrm{kg}$; Vit. E, $106 \mathrm{mg}$; Vit. $\mathrm{K}_{3}, 53 \mathrm{mg}$ e Zn, $2049 \mathrm{mg}$.

${ }^{3}$ Composição calculada segundo o NRC (1998) para animais com alto potencial genético de deposição de carne magra dos 80 aos $120 \mathrm{~kg}$.

3 Calculated composition according NRC (1998) for animals with high genetic potencial for lean gain from 80 to $120 \mathrm{~kg}$

${ }^{4}$ Para o cálculo dos níveis dos aminoácidos digestíveis na ração foram utilizados os coeficientes de digestibilidade para o milho, farelo de soja e glúten de milho recomendados por RHÔNE POULENC (1993).

${ }^{4}$ To calculate the dietary levels of digestible amino acids, the coefficients of digestibility for corn, soybean meal and corn gluten recommended by RHÔNEPOULENC (1993) were considered.

carcaça resfriada).

Para avaliação da conversão alimentar em músculo (CAM), foram utilizados os dados médios de: peso vivo em jejum $\left(\mathrm{P}_{\mathrm{v}} \mathrm{J}\right)$ dos animais, peso da carcaça quente (PCQ), peso da meia-carcaça esquerda (PCE), peso da meia carcaça esquerda fria (PCEF), porcentagem de carne (PC), rendimento de carcaça (RC) e rendimento de frigorificação (RF).

As determinações do RC, RF e CAM foram realizadas de acordo com Fowler et al. (1976), em que:

$\mathrm{RC}=\mathrm{PCQ} / \mathrm{P}_{\mathrm{v}} \mathrm{J} \times 100$

$\mathrm{RF}=\mathrm{PCEF} / \mathrm{PCE} \times 100$

$\mathrm{CAM}=\mathrm{CA} /(\mathrm{RC} \times \mathrm{RF} \times \mathrm{PC}) \times 10^{-6}$
As variáveis de desempenho foram analisadas pelo Sistema de Análises Estatísticas e Genéticas (SAEG), desenvolvido na Universidade Federal de Viçosa (2000), utilizando-se os procedimentos para análises de variância e regressão.

\section{Resultados e Discussão}

As temperaturas, mínimas e máximas, registradas durante o período experimental foram, respectivamente, $17,1 \pm 4,94$ e $24,1 \pm 4,01^{\circ} \mathrm{C}$.

Os resultados de desempenho, consumo estimado de lisina diário e conversão alimentar em conversão 
Tabela 2 - Desempenho de suínos machos castrados, dos 95 aos $110 \mathrm{~kg}$, em função do nível de lisina da ração Table 2 - Performance of barrows from 95 to $110 \mathrm{~kg}$, according to the dietary lysine levels

\begin{tabular}{|c|c|c|c|c|c|c|}
\hline \multirow[t]{2}{*}{$\begin{array}{l}\text { Variáveis } \\
\text { Variables }\end{array}$} & \multicolumn{5}{|c|}{$\begin{array}{l}\text { Níveis de lisina }(\%) \\
\text { Lysine level }(\%)\end{array}$} & \multirow[t]{2}{*}{$\mathrm{CV}(\%)$} \\
\hline & 0,50 & 0,60 & 0,70 & 0,80 & 0,90 & \\
\hline $\begin{array}{l}\text { Ganho de peso (g/dia) }{ }^{1} \\
\text { Weight gain }(\text { g/day) }\end{array}$ & 1042 & 1068 & 1152 & 1035 & 1020 & 12,4 \\
\hline $\begin{array}{l}\text { Consumo de ração }(\mathrm{g} / \text { dia })^{1} \\
\text { Feed intake }(\mathrm{g} / \text { day })\end{array}$ & 3375 & 3289 & 3255 & 3063 & 3030 & 9,0 \\
\hline $\begin{array}{l}\text { Conversão alimentar }(\mathrm{g} / \mathrm{g})^{2} \\
\text { Feed:gain ratio }(\mathrm{g} / \mathrm{g})^{2}\end{array}$ & 3,24 & 3,09 & 2,85 & 2,97 & 2,98 & 7,2 \\
\hline $\begin{array}{l}\text { Consumo estimado de lisina }(\mathrm{g} / \mathrm{dia})^{3} \\
\text { Lysine intake }(\mathrm{g} / \text { day })^{3}\end{array}$ & 16,87 & 19,73 & 22,78 & 24,50 & 27,27 & 9,1 \\
\hline $\begin{array}{l}\text { Conversão alimentar em músculo }(\mathrm{g} / \mathrm{g})^{3} \\
\text { Feed:lean gain }(\mathrm{g} / \mathrm{g})^{3}\end{array}$ & 7,66 & 7,55 & 6,90 & 6,75 & 6,74 & 6,3 \\
\hline $\begin{array}{l}1,3 \text { Efeito linear }(P<0,03) \text { e }(P<0,01) \text {, respec } \\
1,3 \quad \text { Linear effect }(P<0.03) \text { and }(P<0.01) \text {, respective } \\
2 \text { Efeito quadrático }(P<0,10) . \\
2 \quad \text { Quadratic effect }(P<0.10) .\end{array}$ & & & & & & \\
\hline
\end{tabular}

dos suínos machos castrados, dos 95 aos $110 \mathrm{~kg}$, encontram-se na Tabela 2.

Não se observou efeito $(\mathrm{P}>0,10)$ dos níveis de lisina sobre o ganho de peso diário (GPD) dos animais. Resultado similar foi verificado por Johnston et al. (1993) e Witte et al. (2000) em suínos dos 59 aos 120 $\mathrm{kg}$ e dos 90 aos $126 \mathrm{~kg}$, respectivamente, não observando variação do ganho de peso com o aumento no nível de lisina da ração. Contudo, Hahn et al. (1995) constataram variação no GPD dos animais entre 90 e $110 \mathrm{~kg}$, em resposta aos níveis crescentes de lisina na ração, definindo a concentração de $0,59 \%$ para o maior ganho de peso.

Embora a variação do GPD não tenha sido significativa $(\mathrm{P}>0,10)$, houve aumento gradativo que chegou a $10,56 \%$, entre os níveis de 0,5 a $0,7 \%$ de lisina. $\mathrm{O}$ alto coeficiente de variação $(12,4 \%)$, observado para esta variável, foi determinante na ausência de diferença estatística.

Este relato encontra sustentação nos resultados de Cline et al. (2000), em que a variação máxima de 7,9\% ocorrida no GPD dos animais, entre os tratamentos, foi significativa em nível de $1 \%$, embora o coeficiente de variação $(\mathrm{CV})$ tenha correspondido a $5,04 \%$; e nos resultados de Johnston et al. (1993) em que a variação máxima de até $28,0 \%$ no GPD, com o CV correspondendo a $17,27 \%$, não foi significativa.

O nível de lisina influenciou ( $\mathrm{P}<0,03)$ o consumo de ração diário (CRD), que reduziu de forma linear segundo a equação: $\hat{Y}=3850,44-929,743 X$ $\left(r^{2}=0,95\right)$. Este resultado ratifica aqueles obtidos por Chen et al. (1999) e King et al. (2000), quando relataram redução no CRD, devido ao aumento do nível de lisina na ração para suínos na fase de terminação, até os $120 \mathrm{~kg}$ e coerente também com o resultado de Gonçalves et al. (1999), que constataram maior CRD para suínos, na fase de terminação, que receberam a ração com o menor nível calculado de lisina.

Estudando efeitos dos níveis de lisina sobre o desempenho de suínos em terminação, Johnston et al. (1993) constataram redução linear no CRD dos animais entre 59 e $127 \mathrm{~kg}$ e nenhuma variação significativa no consumo de ração dos animais entre 105 e $127 \mathrm{~kg}$.

Por outro lado, diversos autores como Hahn et al. (1995), Tuitoek et al. (1997), Gomes (1998), Souza

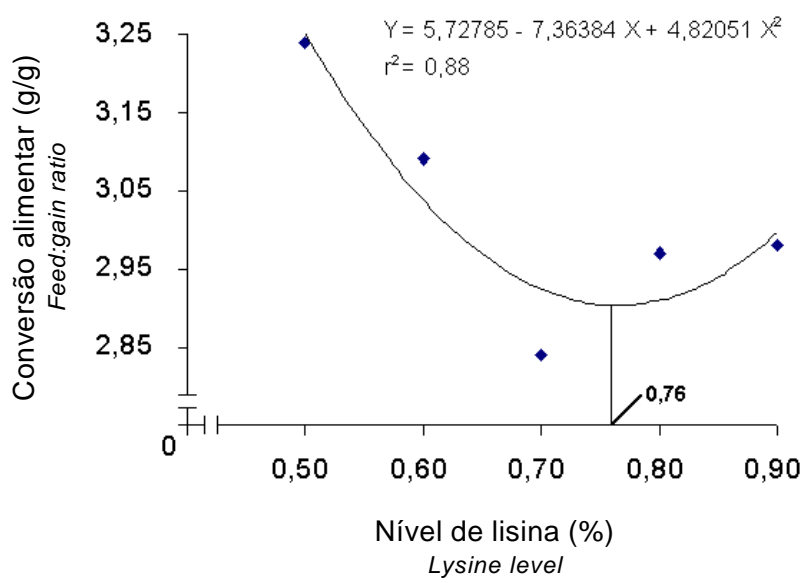

Figura 1 - Efeito do nível de lisina sobre a conversão alimentar de suínos machos castrados com alto potencial genético de 95 a $110 \mathrm{~kg}$.

Figure 1 - Effect of lysine level on feed:gain ratio of barrows with high genetic potential from 95 to $100 \mathrm{~kg}$. 
Filho et al. (1999) e Cline et al. (2000) não verificaram variação significativa no consumo de ração dos animais em razão do nível de lisina.

Os resultados divergentes quanto aos efeitos dos níveis de lisina sobre o CRD dos suínos estão relacionados à diferença entre as faixas de peso avaliadas.

O consumo estimado de lisina diário (CLD) aumentou $(\mathrm{P}<0,01)$ de forma linear em função do nível de lisina na dieta, de acordo com a equação: $\hat{\mathrm{Y}}=4,36195+25,52 \mathrm{X}\left(\mathrm{r}^{2}=0,99\right)$. Aumento no consumo de lisina, em razão da sua inclusão em níveis crescentes na ração, também foi relatado por Johnston et al. (1993) e Cline et al. (2000).

Foi constatado efeito $(\mathrm{P}<0,10)$ dos níveis de lisina sobre a conversão alimentar (CA), que melhorou até o nível de $0,76 \%$ (Figura 1), correspondente a um consumo de lisina estimado de 23,7 g/dia e de 2,26 g de lisina/ $1000 \mathrm{kcal}$ de ED. Resultado similar ao deste estudo foi observado por Hahn et al. (1995), que verificaram variação nos dados de CA de suínos machos castrados, dos 90 aos 110 kg, em razão do aumento no nível de lisina, com melhor resposta no nível correspondente a um consumo diário de 23,2 g de lisina.

Diversos autores (Cromwell et al., 1993; Friesen et al., 1995; Dourmad et al., 1997; Souza, 1997; Loughmiller et al., 1998; King et al., 2000; Witte et al., 2000) encontraram efeito positivo dos níveis de lisina sobre a eficiência de utilização do alimento para ganho de peso em suínos na fase de terminação com peso final acima de $100 \mathrm{~kg}$.

A melhora da CA, até o nível de $0,76 \%$ de lisina, estaria indicando possível modificação na composição do ganho, com aumento na deposição de proteína e redução na deposição de gordura. Esta alteração de ganho, embora possa resultar em menor eficiência energética de ganho (Chen et al., 1999), melhora a eficiência de utilização do alimento por unidade de ganho de peso (Hahn et al., 1995) em razão de o tecido protéico agregar maior quantidade de água, contrariamente ao tecido adiposo.

A melhora na eficiência de utilização do alimento para ganho, entre os níveis de 0,50 a $0,76 \%$ de lisina, correspondeu à diminuição de $46,44 \mathrm{~g}$ de ração/kg de ganho de peso por cada grama de aumento no consumo de lisina.

A conversão alimentar em músculo (CAM) melhorou $(\mathrm{P}<0,01)$ de forma linear com o aumento dos níveis de lisina na ração. No entanto, com o ajuste dos dados pelo modelo LRP estimou-se o nível de 0,79\% de lisina como ótimo (Figura 2). Este resultado

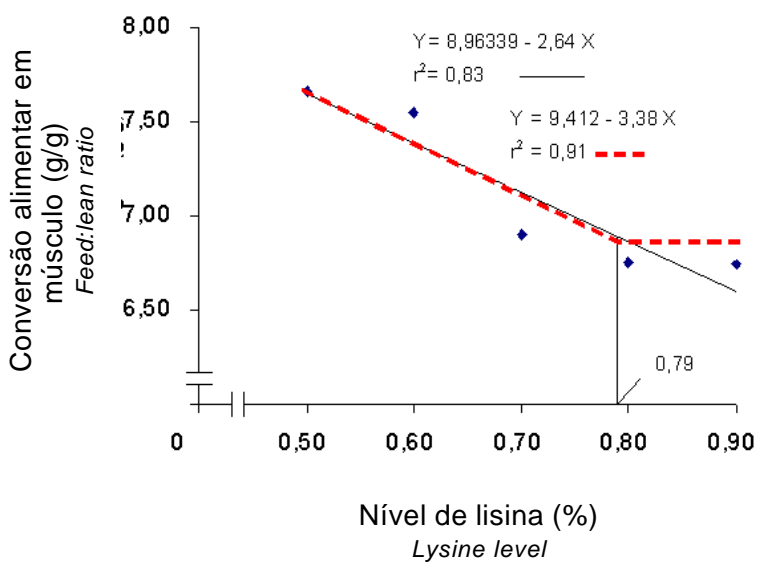

Figura 2 - Efeito do nível de lisina sobre a conversão alimentar em músculo de suínos machos castrados com alto potencial genético de 95 a $110 \mathrm{~kg}$.

Figure 2 - Effect oflysinelevel on feed:leangain of barrows with high genetic potential from 95 to $110 \mathrm{~kg}$.

corrobora o relato de Stahley (1993) em que, quantitativamente, fatores do meio, como a ração, possuem impacto na eficiência de crescimento muscular.

O melhor valor da CAM, de 6,72, encontrado neste trabalho, ficou abaixo dos valores de 7,26 e 7,12 observados por Campabadal \& Navarro (1997) e Gonçalves et al. (1999) em trabalhos conduzidos com suínos machos castrados, dos 22 aos 109 kg e dos 30 aos $130 \mathrm{~kg}$, respectivamente. A diferença nos valores da CAM, verificada entre os trabalhos, pode ser explicada, em parte, pela possível diferença na genética dos animais utilizados, uma vez que, de acordo com Chen et al. (1995), suínos com maior capacidade de deposição de carne utilizam o alimento de maneira mais eficiente, produzindo carcaças com mais carne e menos gordura, quando comparados a animais de baixo potencial para deposição de carne.

Com base nos resultados de CA, CAM e estimativa da ingestão diária de lisina, presume-se que o nível de lisina de $0,60 \%$, correspondente ao consumo de lisina de 17,5 g/dia, preconizados pelo NRC (1998) para suínos de 80 a $120 \mathrm{~kg}$, esteja abaixo do nível ótimo determinado neste estudo.

Os dados das características de carcaça, rendimento de carcaça (RC), rendimento de carne magra (RCM), rendimento de pernil (RP) e rendimento de gordura (RG) de suínos machos castrados, dos 95 aos $110 \mathrm{~kg}$, em razão dos níveis de lisina da ração, encontram-se na Tabela 3. 
Tabela 3 - Comprimento de carcaça pelo método brasileiro (CCMB) e pelo método americano (CCMA), área de olho de lombo (AOL), espessura de toucinho (ETUL), espessura de toucinho a 6,5 cm da linha dorso-lombar (ETP 2 ), rendimento de carcaça $(R C)$, rendimento de carne magra $(R C M)$, rendimento de gordura (RG) e rendimento de pernil (RP) de suínos machos castrados, dos 95 a $110 \mathrm{~kg}$, em função dos níveis de lisina da ração

Table 3 - Brazilian method of lenght carcass (BMLC) and American method of lenght carcass (AMLC), loin eye area (LEA), backfat thickness $(B T)$, backfat thickness at $6.5 \mathrm{~cm}$ from dorso-lumbar line $\left(B T P_{2}\right)$, carcass yield $(C Y)$, lean yield $(L Y)$, fat yield ( $\left.F Y\right)$ and ham yield $(\mathrm{HY})$ of barrows from 95 to $110 \mathrm{~kg}$, in function of the lysine levels of the diet

\begin{tabular}{|c|c|c|c|c|c|c|}
\hline \multirow[t]{2}{*}{$\begin{array}{l}\text { Características } \\
\text { Characteristics }\end{array}$} & \multicolumn{5}{|c|}{$\begin{array}{c}\text { Níveis de lisina (\%) } \\
\text { Lysine level (\%) }\end{array}$} & \multirow[t]{2}{*}{$\mathrm{CV}(\%)$} \\
\hline & 0,50 & 0,60 & 0,70 & 0,80 & 0,90 & \\
\hline $\mathrm{CCMB}(\mathrm{cm})(B M L C, \mathrm{~cm})$ & 97,19 & 97,03 & 97,44 & 97,40 & 97,20 & 1,90 \\
\hline CCMA $(\mathrm{cm})(A M L C, \mathrm{~cm})$ & 83,06 & 80,94 & 80,70 & 81,37 & 80,98 & 2,61 \\
\hline $\operatorname{AOL}\left(\mathrm{cm}^{2}\right)\left(L E A, \mathrm{~cm}^{2}\right)$ & 38,18 & 40,77 & 38,95 & 41,63 & 40,44 & 6,48 \\
\hline $\operatorname{ETUL}(\mathrm{mm})^{*}(B T, \mathrm{~mm})$ & 24,10 & 25,50 & 23,60 & 26,73 & 26,28 & 11,40 \\
\hline $\mathrm{ETP}_{2}(\mathrm{~mm})\left(B T P_{2}, \mathrm{~mm}\right)$ & 16,29 & 17,38 & 16,10 & 16,43 & 16,33 & 9,61 \\
\hline $\mathrm{RC}(\%)(C Y, \%)$ & 83,92 & 83,47 & 83,76 & 83,54 & 84,30 & 1,14 \\
\hline $\operatorname{RCM}(\%)(L Y, \%)$ & 53,42 & 52,14 & 54,13 & 53,63 & 54,33 & 4,13 \\
\hline $\mathrm{RG}(\%)(F Y, \%)$ & 26,20 & 26,13 & 24,81 & 25,09 & 23,89 & 9,20 \\
\hline $\mathrm{RP}(\%)(H Y, \%)$ & 30,02 & 29,42 & 29,34 & 29,38 & 29,85 & 3,60 \\
\hline
\end{tabular}

${ }^{\star}$ Espessura de toucinho entre a última e a penúltima vértebra lombar.

* Backfat thickness between last and next to the last lumbar vertebra.

Não se constatou efeito $(\mathrm{P}>0,10)$ dos níveis de lisina sobre nenhuma das características de carcaça e rendimento de cortes avaliados. Resultados similares foram obtidos por Friesen et al. (1995) e Hahn et al. (1995), que não observaram efeito de níveis de lisina sobre a área de olho de lombo (AOL) e espessura de toucinho na décima vértebra lombar (ET 10를 $)$ de leitoas abatidas aos $104 \mathrm{~kg}$ e de machos castrados abatidos aos $108 \mathrm{~kg}$, respectivamente.

O mesmo foi observado por Grandhi \& Cliplef (1997) e Souza Filho et al. (1999), que não constataram efeito do nível de lisina sobre a AOL, sobre a espessura de toucinho no $\mathrm{P}_{2}\left(\mathrm{ETP}_{2}\right)$ e o rendimento de carne magra (RCM), em suínos com alto potencial genético para deposição de carne magra, abatidos aos 130 e $105 \mathrm{~kg}$, respectivamente.

Apesar da coerência entre os dados de carcaça nos trabalhos, o valor médio de $40 \mathrm{~cm}^{2}$ de AOL, encontrado neste estudo foi superior aos valores médios de 37,2, $38,6 \mathrm{e} 31,3 \mathrm{~cm}^{2}$, respectivamente observados por Friesen et al. (1995), Hahn et al. (1995) e Grandhi \& Cliplef (1997); e similar ao valor médio de $40,1 \mathrm{~cm}^{2}$ obtido por Gonçalves et al. (1999).

A diferença na capacidade de deposição de carne magra na carcaça dos animais utilizados nos diferentes trabalhos pode ter contribuído para a variação nos resultados de AOL observados. Estudando a composição corporal de suínos, dos 25 aos $152 \mathrm{~kg}$, de cinco diferentes populações genéticas, Wagner et al. (1999) constataram que a AOL variou de 27,68 a 35,91 cm² para machos castrados abatidos aos $114 \mathrm{~kg}$. Os resultados obtidos de características de carcaça e rendimento de cortes corroboram o relato de Unruh et al. (1996), que, avaliando a influência do genótipo, sexo e níveis de lisina sobre os dados de carcaça de suínos abatidos aos 104 e aos $127 \mathrm{~kg}$, verificaram que o nível de lisina da ração tem mínima influência nas características de carcaça de suínos de diferentes genótipos e sexo.

Apesar de não ter ocorrido variação nos diferentes parâmetros de carcaça avaliados neste estudo, com o aumento dos níveis de lisina na ração, constatou-se que o rendimento de gordura $(\mathrm{RG})$ tendeu a diminuir $(\mathrm{P}<0,12)$ de forma linear. A diferença entre os tratamentos chegou a 8,78\%, à medida que se elevaram os níveis de lisina na ração.

A redução na quantidade de gordura na carcaça, obtida neste trabalho, pode estar relacionada à diminuição gradativa no consumo de energia entre os tratamentos, que chegou a representar 10,24\%, correspondente a uma diferença no consumo de até $1164 \mathrm{kcal} /$ dia de ED. Estudando níveis de lisina para leitoas híbridas, dos 90 aos $126 \mathrm{~kg}$, Witte et al. (2000) constataram variação significativa somente na espessura de toucinho, medida na décima costela (ET10 a $)$, sendo que as outras avaliações de espessura de toucinho feitas na $1 \stackrel{\mathrm{a}}{\mathrm{c}}$ costela, última costela e última vértebra lombar não variaram.

Com base nos resultados de ETP $_{2}$ e RG, pode-se inferir que a espessura de toucinho, medida no $\mathrm{P}_{2}$, não foi uma variável adequada para retratar variação no teor de gordura da carcaça entre os tratamentos estudados. 


\section{Conclusões}

Suínos machos castrados, dos 95 aos $110 \mathrm{~kg}$, exigem $0,76 \%$ de lisina, correspondente a um consumo de lisina diário de $23,8 \mathrm{~g}$.

\section{Agradecimento}

ÀAGROCERESNUTRIÇÃOANIMAL, pelacessão dos animais e dos ingredientes das rações experimentais.

\section{Literatura Citada}

ASSOCIAÇÃO BRASILEIRA DE CRIADORES DE SUÍNOS ABCS. Método brasileiro de classificação de carcaça. Estrela, RS. 1973. 17p.

BOGGS, D.L.; MERKEL, R.A. Live animal carcass evaluation and selection manual. Toronto: Kendall/Hunt, 1979. 199p.

CAMPABADAL, C.; NAVARRO, H. Importancia de la nutrición en la producción de canales magras de cerdo. Asociación Americana de Soya. Medellín: Colombia. SOYANOTICIAS, 1997.

CHEN, H.Y.; MILLER, T.S.; LEWIS, A.J. et al. Changes in plasma urea concentration can be used to determine protein requirements of two populations of pigs with different protein accretion rates. Journal of Animal Science, v.73, n.9, p.2631-2639, 1995.

CHEN, H.Y.; LEWIS, A.J.; MILLER, P.S. et al. The effect of excess protein on growth performance and protein metabolism of finishing barrows and gilts. Journal of Animal Science, v.77, n.12, p.3238-3247, 1999.

CLINE, T.R.; CROMWELL, G.L.; CRENSHAW, T.D. et al. Further assessment of the dietary lysine requirement of finishing gilts. Journal of Animal Science, v.78, n.4, p.987-992, 2000.

CROMWELL, G.L.; CLINE, T.R.; CRENSHAW, J.D. et al. The dietary protein and (or) lysine requirements of barrows and gilts. Journal of Animal Science, v.71, n.6, p.1510-1519, 1993.

DOURMAD, J.Y.; GUILLOU, D.; SÈVE, B. et al. Response to dietary lysine supply during the finishing period in pigs. Livestock Production Science, v.45, n.2-3, p.179-186, 1996.

FOWLER, V.R.; BICHARD, M.; PEASE, A. Objectives in pig breeding. Animal Production, v.23, p.365-387, 1976.

FRIESEN, K.G.; NELSSEN, J.L.; GOODBAND, R.D. et al. Influence of dietary lysine on growth and carcass composition of high-lean-growth gilts fed from 72 to 126 kilograms. Journal of Animal Science, v.72, n.7, p.1761-1770, 1985.

FULLER, M. Macronutrient requirements of growing swine. In: SIMPÓSIO INTERNACIONAL SOBRE EXIGÊNCIAS NUTRICIONAIS DE AVES E SUÍNOS, 1996, Viçosa, MG. Anais... Viçosa, MG: Universidade Federal de Viçosa, 1996. p. 206.

GOMES, F.E. Planos de nutrição baseados em níveis de lisina para suínos de diferentes genótipos abatidos aos 80 e $100 \mathrm{~kg}$ de peso vivo. Lavras: Universidade Federal de Lavras, 1998. 55p. Dissertação (Mestrado em Zootecnia) - Universidade Federal de Lavras, 1998.

GONÇALVES, T.M.; BETERCHINI, A.G.; KONING, G. et al. Sexo, níveis de energia e lisina e período experimental para suínos híbridos na fase de crescimento-terminação. In: REUNIÃO ANUAL DA SOCIEDADE BRASILEIRA DEZOOTECNIA, 1999, 26., Porto Alegre. Anais... Porto Alegre: Sociedade Brasileira de Zootecnia, 1999. (CD ROM)
GRANDHI, R.R.; CLIPLEF, R.L. Effects of selection for lower backfat, and increased levels of dietary amino acids to digestible energy on growth performance, carcass merit and meat quality in boars, gilts, and barrows. Canadian Journal of Animal Science, v.77, n.3, p.487-496, 1997.

HAHN, J.D.; BIEHL, R.R.; BAKER, D.H. Ideal digestible lysine for early and late-finishing swine. Journal of Animal Science, v.73, n.3773-784, 1995.

JOHNSTON, M.E.; NELSSEN, J.L.; GOODBAND, R.D. et al. The effects of somatotropin and dietary lysine on growth performance and carcass characteristics of finishing swine fed to 105 or 127 kilograms. Journal of Animal Science, v.71, n.11, p.2986-2995, 1993.

KING, R.H.; CAMPBELL, R.G.; SMITS, R.J. et al. Interrelationships between dietary lysine, sex, and porcine somatotropin administration on growth performance and protein deposition in pigs between 80 and $120 \mathrm{~kg}$ live weight. Journal of Animal Science, v.78, n.10, p.2639-2651, 2000.

LOUGHMILLER, J.A.; NELSSEN, J.L.; GOODBAND, R.D. et al. Influence of dietary lysine on growth performance and carcass characteristics of late-finishing gilts.Journal of Animal Science, v.76, n.4, p.1075-1080, 1998.

NATIONAL RESEARCH COUNCIL - NRC. Nutrient requirements of swine. 10.ed., Washington, D.C.: National Academy Press, 1998. 189p.

RHÔNE POULENC. Nutrition guide Rhône Poulenc Animal Nutrition - France. 2.ed. 1993. 55p.

SILVA, D.J.Análise de alimentos (Métodos químicos e biológicos). Viçosa, MG: Universidade Federal de Viçosa, 1990. 160p.

SOUZA, A.M. Exigências nutricionais de lisina para suínos mestiços, de 15 a $95 \mathrm{~kg}$ de peso. Viçosa, MG: Universidade Federal de Viçosa, 1997. 81p. Dissertação (Mestrado em Zootecnia) - Universidade Federal de Viçosa, 1997.

SOUZA FILHO, G.A.; LIMA, J.A.F.; FIALHO, E.T. et al. Efeito de planos de nutrição e de genótipos sobre características físicas de carcaça de suínos. In: REUNIÃO ANUALDA SOCIEDADE BRASILEIRA DE ZOOTECNIA, 1999, 26., Porto Alegre. Anais... Porto Alegre: Sociedade Brasileira de Zootecnia, 1999. (CD ROM)

STAHLEY, T. Nutrition effects lean growth, carcass composition. Feedstuffs, v.65, n.26, p.12, 1993.

TUITOEK, K.; YOUNG, L.G.; LANGE, C.F.M. et al. The effect of reducing excess dietary amino acids on growing-finishing pig performance: an evaluation of the ideal protein concept.Journal of Animal Science, v.75, n.6, p.1575-1583, 1997.

UNRUH, J.A.; FRIESEN, K.G.; STUEWE, S.R. et al. The influence of genotype, sex, and dietary lysine on pork subprimal cut yields and carcass quality of pigs fed to either 104 or 127 kilograms. Journal of Animal Science, v.74, n.6, p.12741283, 1996.

UNIVERSIDADE FEDERAL DE VIÇOSA (UFV). S.A.E.G. (Sistemas de Análises Estatísticas e Genéticas). Viçosa, MG (Versão 8.0). 2000.

WAGNER, J.R.; SCHINCKEL, A.P.; CHEN, W. et al. Analysis of body composition changes of swine during growth and development. Journal of Animal Science, v.77, n.6, p.14421466, 1999.

WITTE, D.P., ELLIS, M.; McKEITH, F.K. et al. Effect of dietary lysine and environmental temperature during the finishing phase on the intramuscular fat content of pork. Journal of Animal Science, v.78, n.5, p.1272-1276, 2000.

Recebido em: 16/05/01 Aceito em: 07/10/02

R. Bras. Zootec., v.32, n.2, p.337-343, 2003 